\title{
Hepatoblastoma: glutamine depletion hinders cell viability in the embryonal subtype but high GLUL expression is associated with better overall survival
}

\author{
Andreas Schmidt ${ }^{1} @ \cdot$ Angela Armento $^{1,2} \cdot$ Ovidio Bussolati $^{3} \cdot$ Martina Chiu $^{3} \cdot$ Verena Ellerkamp $^{1}$. \\ Marcus O. Scharpf ${ }^{4} \cdot$ Philip Sander $^{4} \cdot$ Evi Schmid $^{1} \cdot$ Steven W. Warmann ${ }^{1} \cdot$ Jörg Fuchs ${ }^{1}$
}

Received: 20 December 2020 / Accepted: 24 June 2021 / Published online: 7 July 2021

(c) The Author(s) 2021

\begin{abstract}
Purpose Glutamine plays an important role in cell viability and growth of various tumors. For the fetal subtype of hepatoblastoma, growth inhibition through glutamine depletion was shown. We studied glutamine depletion in embryonal cell lines of hepatoblastoma carrying different mutations. Since asparagine synthetase was identified as a prognostic factor and potential therapeutic target in adult hepatocellular carcinoma, we investigated the expression of its gene ASNS and of the gene $G L U L$, encoding for glutamine synthetase, in hepatoblastoma specimens and cell lines and investigated the correlation with overall survival.

Methods We correlated GLUL and ASNS expression with overall survival using publicly available microarray and clinical data. We examined GLUL and ASNS expression by RT-qPCR and by Western blot analysis in the embryonal cell lines Huh- 6 and HepT1, and in five hepatoblastoma specimens. In the same cell lines, we investigated the effects of glutamine depletion. Hepatoblastoma biopsies were examined for histology and CTNNB1 mutations.

Results High GLUL expression was associated with a higher median survival time. Independent of mutations and histology, hepatoblastoma samples showed strong GLUL expression and glutamine synthesis. Glutamine depletion resulted in the inhibition of proliferation and of cell viability in both embryonal hepatoblastoma cell lines. ASNS expression did not correlate with overall survival.

Conclusion Growth inhibition resulting from glutamine depletion, as described for the hepatoblastoma fetal subtype, is also detected in established embryonal hepatoblastoma cell lines carrying different mutations. At variance with adult hepatocellular carcinoma, in hepatoblastoma asparagine synthetase has no prognostic significance.
\end{abstract}

Keywords Hepatoblastoma $\cdot$ Hepatocellular carcinoma $\cdot$ Glutamine depletion $\cdot$ Glutamine synthetase $\cdot$ Asparagine synthetase $\cdot$ Asparaginase

Andreas Schmidt

andreas.schmidt@med.uni-tuebingen.de

1 Department of Paediatric Surgery and Paediatric Urology, University Children's Hospital, Eberhard Karls University Tuebingen, Hoppe-Seyler-Strasse 3, 72076 Tuebingen, Germany

2 Department for Ophthalmology, Institute for Ophthalmic Research, University of Tuebingen, Elfriede-Aulhorn-Straße 7, 72076 Tuebingen, Germany

3 Department of Medicine and Surgery (DiMeC), University of Parma, Parma, Italy

4 Institute for Pathology and Neuropathology, Department of General Pathology and Pathological Anatomy, Eberhard Karls University Tuebingen, Liebermeisterstr. 8, 72076 Tuebingen, Germany

\section{Introduction}

The amino acid glutamine (Gln) is involved in key cellular processes, such as energy metabolism, nucleotide biosynthesis, the balance of redox potential, and in various signaling pathways (DeBerardinis and Cheng 2010). Dependence on Gln has been described for several tumors, and Gln metabolism has been identified as a promising target in tumor therapy (Lukey et al. 2013; Martinez-Outschoorn et al. 2017; Still and Yuneva 2017). Therapeutic options that target Gln synthesis and metabolism are being investigated for selected tumors (Mates et al. 2020; Schulte, 2018; Ye, 2018).

Gln is synthesized by the enzyme glutamine synthetase (GS or GLUL glutamate-ammonia ligase), encoded by the 
gene GLUL. In hepatic models, the transcription of this gene is primarily regulated by the $\mathrm{Wnt} / \beta$-catenin pathway. Activation of this signaling pathway through Wnt ligands prevents $\beta$-catenin degradation in the cytosol, allowing $\beta$-catenin to migrate into the nucleus where it increases the transcription of GLUL by interacting with the transcription factors TCF and LEF (Monga 2015; Willert and Nusse 1998). Mutations in the gene for $\beta$-catenin, CTNNB1, result in reduced degradation and, thus, in increased $G L U L$ expression and activity (Cadoret, 2002; Lopez-Terrada, 2009b).

Hepatoblastomas (HB), the most common malignant liver tumors in children, carry up to $90 \%$ deletions and/or missense mutations in the CTNNB1 gene (Cairo, 2008; Eichenmuller, 2014; Koch et al. 1999; Lopez-Terrada et al. 2009b; Sumazin, 2017). Activation of the $\mathrm{Wnt} / \beta$-catenin pathway is reported in $97 \%$ of hepatoblastomas, given that mutations in other components of the pathway may also lead to its activation (Jia, 2014; Koch et al. 1999, 2004; Sumazin et al. 2017).

Histology of HB presents heterogeneous tumors consisting mainly of epithelial components with fetal and embryonal parts, as well as mesenchymal and undifferentiated small cell components (Lopez-Terrada, 2014). Prognosis correlates with histology and ranges from very good, for the pure fetal type, to poor for the undifferentiated small cell type (Czauderna et al. 2014; Haas et al. 2001, 1989; Malogolowkin et al. 2011; Zimmermann 2005).

Studies on the effect of glutamine depletion were performed with the hepatoblastoma cell line HepG2, representing the fetal tumor subtype (Crippa, 2017; Lopez-Terrada et al. 2009a) and on its murine xenografts. Glutamine depletion reduced cell viability in vitro and the growth of xenografts in vivo (Chiu, 2014; Tardito, 2011).

Since the tumor subtypes are different in gene expression and metabolism, we investigated the effect of glutamine depletion, GLUL expression, and GS abundance in the hepatoblastoma cell lines Huh-6 and HepT1, which differ in their mutations and, in contrast to the fetal-type HepG2, derive from tumors of the embryonal subtype (Crippa et al. 2017; Koch et al. 1999; Pietsch et al. 1996).

Because of the relationship between Gln and asparagine (Asn) metabolism, we investigated expression of the gene $A S N S$, which encodes asparagine synthetase (ASNS), and ASNS abundance along with GLUL expression and GS abundance in the two cell lines and in biopsies of hepatoblastoma patients. Besides histological staining, we examined patient biopsies for CTNNB1 mutations. Additionally, since ASNS was identified as a prognostic parameter in hepatocellular carcinoma (Zhang, 2013), we investigated the association between overall survival of patients and GLUL and $A S N S$ expression, exploiting publicly available microarray data.

\section{Materials and methods}

\section{Patients and tissue samples}

Expression of GLUL and ASNS was evaluated from published expression databases (http://www.ebi.ac.uk/micro array-as/ae/; E-MEXP-1851 (Cairo et al, 2008)). The databases include $25 \mathrm{HB}$ samples and 4 non-tumor liver samples, which were analyzed by Affymetrix oligonucleotide array (Affymetrix U133A2.0; Affymetrix, Santa Clara, $\mathrm{CA})$. Relative expression of the genes is given as signal $\log$ ratio (SLR). For all $25 \mathrm{HB}$ samples, the differentiation into the molecular subclasses C1- and C2-type, as well as survival data, has been previously reported (Cairo et al. 2008). For one patient follow-up data are missing, and the relevant data were censored in the analysis. We used these published microarray and clinical data to analyze the correlation between gene expression and overall survival.

Five samples from our human hepatoblastoma tissue collection with epithelial-fetal $(n=3)$ epithelial-embryonal $(n=1)$ and mixed epithelial-mesenchymal $(n=1)$ histology were analyzed for mutations on exon 3 of $C T N N B 1$ as well as for GLUL and ASNS expression on mRNA level and abundance of the respective proteins.

\section{Western Blot}

Hepatoblastoma tumor specimens were immediately fixed in liquid nitrogen and stored at $-80{ }^{\circ} \mathrm{C}$ for further analysis Hepatoblastoma tissue samples were homogenized with an Ultra Turrax (IKA) instrument in RIPA lysis buffer (Cell Signaling, Germany) containing a cocktail of protease inhibitors (Roche) and centrifuged at 14,000 $\mathrm{g}$ for $20 \mathrm{~min}$ at $4{ }^{\circ} \mathrm{C}$. Aliquots of $30 \mu \mathrm{g}$ of proteins in Roti Load ${ }^{\circledR}$ buffer $4 \mathrm{x}$ (Carl Roth) were warmed at $95^{\circ} \mathrm{C}$ for $5 \mathrm{~min}$ and loaded on a $10 \%$ gel for SDS-PAGE.

Cells were lysed in a buffer containing $20 \mathrm{mM}$ Tris-HCl, pH 7.5, $150 \mathrm{mM} \mathrm{NaCl}, 1 \mathrm{mM}$ EDTA, $1 \mathrm{mM}$ EGTA, $1 \%$ Triton, $2.5 \mathrm{mM}$ sodium pyrophosphate, $1 \mathrm{mM}$ $\beta$-glycerophosphate, $1 \mathrm{mM} \mathrm{Na} \mathrm{VO}_{4}, 1 \mathrm{mM} \mathrm{NaF}, 2 \mathrm{mM}$ imidazole and a cocktail of protease inhibitors (Protease Inhibitor Cocktail, Sigma-Aldrich). Lysates were transferred in Eppendorf tubes, sonicated for $5 \mathrm{~s}$ and centrifuged at $12,000 \mathrm{~g}$ for $10 \mathrm{~min}$ at $4{ }^{\circ} \mathrm{C}$. Protein determination was performed with Coomassie Brilliant Blue G-250 acid solution (Bio-Rad protein assay). Absorbance at $750 \mathrm{~nm}$ was read, and protein content was calculated from bovine serum albumin standards. Aliquots of $30 \mu \mathrm{g}$ of proteins were mixed with Laemmli buffer $4 \mathrm{x}(250 \mathrm{mM}$ Tris- $\mathrm{HCl}$, pH 6.8, 8\% SDS, 40\% glycerol, and 0.4 M DTT), warmed at $95^{\circ} \mathrm{C}$ for $5 \mathrm{~min}$ and loaded on a $10 \%$ gel for SDS-PAGE. 
After electrophoresis, proteins were transferred to nitrocellulose membranes (Millipore). To block non-specific binding sites, an incubation of $1 \mathrm{~h}$ at room temperature in $10 \%$ non-fat dried milk (Carl Roth, Germany) in TBS-T solution was performed. The next step was the incubation of the blots at $4{ }^{\circ} \mathrm{C}$ overnight with the following antibodies diluted in a 5\% BSA TBS-Tween solution: anti-GS (rabbit, polyclonal, 1:1000, GeneTex, \#GTX109121), anti-ASNS (rabbit, monoclonal, 1:500, Cell Signaling, Frankfurt am Main, Germany, \#92479) and anti-GADPH (rabbit, monoclonal, 1:2000, Cell Signaling, \#2118). Blots were then washed and exposed for $1 \mathrm{~h}$ at room temperature to HRPlinked anti-rabbit antibody (Cell Signaling, \#7074) diluted 1:3000 in 5\% non-fat dried milk. Visualization of immunoreactivity was performed with a Western Sure Premium Chemiluminescent Substrate (LI-COR, Lincoln, Nebraska, USA). Specific bands were quantified by LI-COR Image Studio software (LI-COR, Lincoln, Nebraska, USA). Levels of each protein were expressed as the ratio of signal intensity for the target protein relative to that of GAPDH (Schmidt et al. 2014).

\section{Cell culture}

The two HB cell lines Huh-6 (Doi 1976) and HepT1 (Pietsch et al. 1996) were used for this study. The Huh-6 cell line was bought from the Japanese Collection of Research Bioresources (Huh-6 Clone 5; JCRB0401, RRID:CVCL_1296). Members of our research laboratory were part of the group that implemented the hepatoblastoma cell line HepT1 (RRID:CVCL_G003). As a result, we have access to this cell line. All used cells were tested negative for mycoplasma. Mycoplasma detection was determined according to the manufacturer's instructions (MycoAlert ${ }^{\mathrm{TM}}$, Mycoplasma Detection Kit, Lonza, Basel, Switzerland). Cells were grown in high-glucose ( $4.5 \mathrm{~g} / \mathrm{l})$ Dulbecco's modified Eagle's medium (DMEM); supplemented with $2 \mathrm{mM}$ glutamine, $10 \%$ of fetal bovine serum (FBS), $100 \mathrm{U} / \mathrm{ml}$ penicillin, and $100 \mu \mathrm{g} / \mathrm{ml}$ streptomycin. All reagents were from Biochrom, Berlin, Germany. Cells were seeded at a density of $2 \times 10^{4}$ cells per well in complete growth medium in 24-well plates in triplicates.

For viability assays, after $24 \mathrm{~h}$ the culture medium was substituted with fresh complete medium supplemented with asparaginase (ASNase) (E. chrisanthemy ASNase, Erwinase ${ }^{\circledR}$, Jazz Pharmaceuticals, UK), the GS inhibitor methionine-L-sulfoximine (MSO) (Sigma-Aldrich, Munich, Germany), or a combination of both substances. ASNase was used at seven concentrations from 0.003 to $10 \mathrm{U} / \mathrm{ml}$ for cell number experiments, and at six concentrations from 0.003 to $1 \mathrm{U} / \mathrm{ml}$ for MTT-assay, while MSO was used at $1 \mathrm{mM}$. The effects of ASNase and MSO on cell cultures were assessed counting viable cells with a Coulter Z1 particle counter $72 \mathrm{~h}$ later or by means of a colorimetric MTT-assay measuring the reduction of tetrazolium salts to formazan derivatives by functional mitochondria. Lysis buffer (DMSO, SDS, acid) were added to solubilize the blue MTT-formazan product. The assays were performed in triplicates as originally described (Mosmann 1983). Absorbance was measured at $570 \mathrm{~nm}$.

To determine the effect of ASNase on mRNA and protein levels of GS and ASNS, after $24 \mathrm{~h}$ the culture medium was substituted with fresh complete medium supplemented with ASNase $(1 \mathrm{U} / \mathrm{ml})$, ASNase $(1 \mathrm{U} / \mathrm{ml})$ and MSO $(1 \mathrm{mM})$, or with standard growth medium for controls. mRNA and protein were analyzed 6 and $24 \mathrm{~h}$ later, and protein also after $48 \mathrm{~h}$.

\section{RT-qPCR analysis}

Total RNA was isolated from Huh-6 and HepT1 cells using the GenElute ${ }^{\mathrm{TM}}$ Mammalian Total RNA Miniprep Kit (Sigma-Aldrich, Munich, Germany). Hepatoblastoma samples were immediately preserved in RNAlater ${ }^{\circledR}$ (Qiagen, Hilden, Germany) and stored at $-80{ }^{\circ} \mathrm{C}$ for further RNA analysis. The tissue samples were homogenized in RLT buffer (including DTT) using an Ultra Turrax (IKA, Staufen, Germany) instrument. Total RNA was isolated from hepatoblastoma samples using the RNeasy mini kit by following the manufacturer's instructions (Qiagen, Hilden, Germany). cDNA synthesis was performed using High capacity cDNA Reverse Transcription Kit (Applied Biosystems, Waltham, Massachusetts, USA). Reverse transcription and semiquantitative PCR were performed as described by Chiu et al, 2014. Primers used for ASNS were 5' GATTGCCTTCTG TTCAGTGTCT 3' (for) and 5' GGGTCAACTACCGCC AACC 3' (rev), for GLUL 5' TCATCTTGCATCGTGTGT GTG 3' (for) and 5' CTTCAGACCATTCTCCTCCGG 3' (rev), and for Axin-2 5' AGGGAGAAATGCGTGGATAC 3' (for) and 5' TGGAATCAATCTGCTGCTTC 3' (rev). Housekeeping genes were Ribosomal protein L15 (RPL15) 5' GCAGCCATCAGGTAAGCCAAG 3' (for) and 5' AGC GGACCCTCAGAAGAA AGC 3' (rev) for the experiments with cells and TBP (TATA binding protein, 5' GCC CGA AAC GCC GAA TAT 3' (for) and 5'CCG TGG TTC GTG GCT CTC 3' (rev)) for experiments with tissue samples. TBP (TATA Box Binding Protein) was used as reference gene in RT-PCR analysis as it is directly involved in transcriptional activity of a gene and correlates with the transcriptional activity of the promoter region. GAPDH, on the other hand, is one of the top 20 housekeeper with the highest and most consistent average expression (She et al. 2009) and was thus chosen for comparison of protein expression of respective genes. For data analysis, the $\Delta \Delta \mathrm{CT}$ method was used (Livak and Schmittgen 2001). Specificity of PCR 
products was confirmed by analysis of a melting curve. Realtime amplifications were performed on a $\mathrm{C} 1000^{\mathrm{TM}}$ Thermo Cycler (Bio-rad, Feldkirchen, Germany).

\section{Next-generation-sequencing (NGS) of CTNNB1 exon 3}

Genomic DNA was extracted from macro-dissected $5 \mu \mathrm{m}$ paraffin sections using the Maxwell ${ }^{\circledR}$ RSC DNA FFPE Kit and the Maxwell ${ }^{\circledR}$ RSC Instrument (Promega, Madison, WI, USA) according to the manufacturer's instructions.

CTNNB1 exon 3 was investigated by next generation sequencing with a single amplicon using the Ion Amplicon Library Preparation Fusion Method (ThermoFisher Scientific, Waltham, MA, USA) according to the manufacturer's protocol (gene specific primer sequences identical to Sanger sequencing: Fwd: 5'-TGGAACCAGACAGAA AAGCG-3' and Rev: 5'-CAGGTACCGTGCGACATC-3'). Amplicons were purified and quantified applying Agencourt AMPure XP magnetic beads (Beckman Coulter, Brea, CA, USA) and the Qubit dsDNA HS Assay Kit (Thermo Fisher Scientific), respectively. Amplicons were diluted to $5 \mathrm{pM}$ each and pooled. Clonal amplification and semiconductor sequencing was done according to the manufacturer's manuals using the Ion $510^{\mathrm{TM}}$ and Ion $520^{\mathrm{TM}}$ and Ion $530^{\mathrm{TM}} \mathrm{Kit}-$ Chef (ThermoFisher Scientific) on the Ion Chef ${ }^{\mathrm{TM}}$ Instrument (ThermoFisher Scientific) and the Ion 520 ${ }^{\mathrm{TM}}$ Chip Kit on the Ion GeneStudio ${ }^{\mathrm{TM}}$ S5 Prime system (ThermoFisher Scientific). BAM Files were generated with Torrent Suite 5.10.2. Sequences were visualized and evaluated using the freely available software Integrative Genomics Viewer (IGV, Broad Institute).

\section{Statistical analysis}

Survival curves were calculated using the Kaplan-Meier method and compared using the log-rank test. Data of $G L U L$ and $A S N S$ expression levels were expressed as mean \pm SD. The relationship between GLUL and ASNS expression was analyzed with the use of Pearson correlation. Two-tail $t$ test for unpaired samples was used to detect differences between groups. $p$ values below 0.05 were considered statistically significant. All statistical analyses were conducted with the use of GraphPad Prism 5.0 ${ }^{\mathrm{TM}}$.

\section{Results}

\section{Expression of GLUL and ASNS in hepatoblastoma}

Data of expression databases revealed that GLUL and ASNS are overexpressed in HB compared to non-tumor liver tissue. All HB except one showed a higher GLUL expression than the non-tumour tissue. Relative GLUL expression levels for $\mathrm{HB}$ and the non-tumor tissue were $12.4 \pm 1.3$ and $9.7 \pm 0.4$, respectively $(p=0.0003)$. All $\mathrm{HB}$ exhibited a higher ASNS expression than the non-tumor tissue (SLR 7.0 \pm 1.1 and SLR 5.5 $\pm 0.1, p=0.01)$. Pearson's correlation coefficient for GLUL and ASNS expression in tumor samples is $r=-0.57$ (Fig. 1A).

To further investigate the significance of the expression levels, we examined the distribution of the expression levels and the association with patients' survival. The scatter plots of GLUL and ASNS expression revealed a high and a low expression group separated by a cut off value of SLR 12.0 for GLUL and of SLR 6.75 for ASNS (Fig. 1C and D). The GLUL-high (SLR 13.2 \pm 0.4 ) and the GLUL-low (SLR $10.7 \pm 0.5$ ) as well as the ASNS-high (SLR 7.8 \pm 0.8 ) and the ASNS-low (SLR 6.1 \pm 0.3 ) groups were statistically different $(p<0.001)$. Low $G L U L$ expression was associated with a reduced median overall survival of 68 months (Fig. 1E) compared to the high expression group (median of overall survival not reached); for group comparison, the log rank test revealed a $p=0.1855$. Median overall survival of the $A S N S$ high and low expression group has not been reached (group comparison: $p=0.7125$ ) (Fig. 1F).

We further assessed (Fig. 1B) if these results are in line with conclusions drawn from the molecular classification scheme of HB based on the genetic profile and differentiating tumors in type $\mathrm{C} 1$ and type $\mathrm{C} 2$, type $\mathrm{C} 2$ being associated with a more advanced tumor stage and poor prognosis (Cairo et al. 2008). C1-type HB exhibited a higher GLUL expression (SLR 12.5 \pm 1.1 ) than the C2-type HB (SLR 11.3 \pm 1.5 ) $(p=0.03)$. The difference in ASNS expression of the two groups (C1: SLR $6.8 \pm 0.9$ and C2: SLR 7.4 \pm 1.4$)$ was not significant $(p=0.26)$. These data indicate that $G L U L$ expression is associated more than ASNS expression with overall survival and tumor stage in HB.

\section{Mutations in exon 3 of CTNNB1 and expression of GLUL and ASNS in human HB samples}

Two of the five human HB samples, the epithelial-embryonal and one of the epithelial-fetal HBs, carried a mutation in exon 3 of CTNNB1. Both mutations were point mutations (Table 1). To further analyze the samples for activation of the Wnt pathway, we investigated the expression of the Axin2 gene, a target of $\beta$-catenin. RT-qPCR analysis of Axin- 2 expression revealed a higher expression in all HB samples compared to normal liver tissue, even in samples without CTNNB1 mutation (Fig. 2).

From the RT-qPCR analysis (Fig. 3A), all HB samples except HB16 showed an increased GLUL expression compared to normal liver tissue. GS levels in Western blots of tumor samples HB16 and HB53 and normal liver tissue 


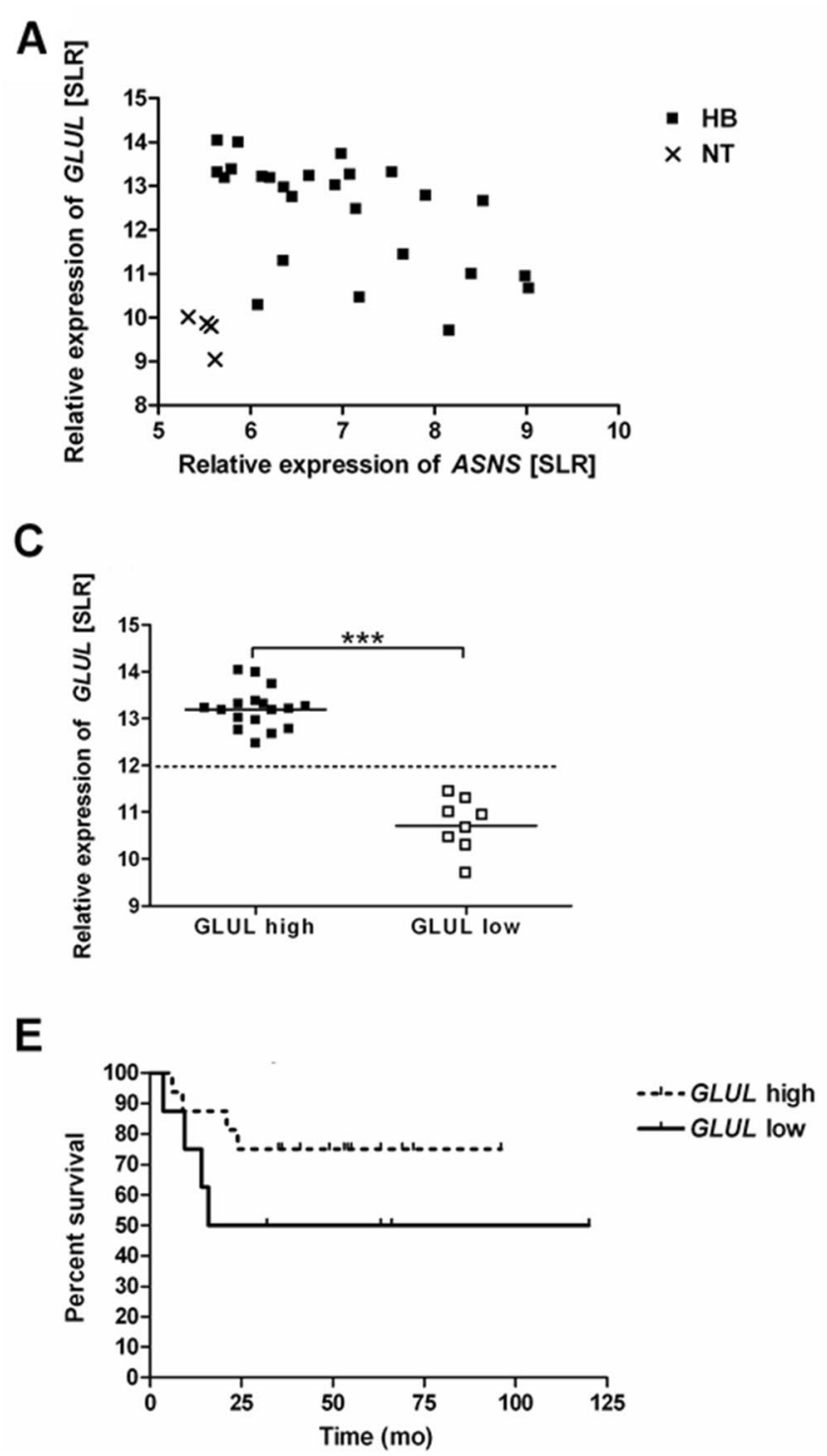

Fig. 1 GLUL and ASNS expression in $\mathrm{HB}$ and overall survival. GLUL and ASNS expression levels of HB $(n=25)$ and normal liver tissues (NT) $(n=4)$ samples are shown. Each data point reflects the GLUL and ASNS level of one sample. Relative expression levels of genes are given as signal log ratio (SLR). A Scatter plot of the data. Expression of GLUL and ASNS is significant higher in HB than in NT $(p=0.0003$ and $p=0.01$, respectively). Pearson's correlation coefficient for GLUL and ASNS expression is $r=-0.57$. B Expression levels according to $\mathrm{C} 1$ and $\mathrm{C} 2$ tumour type. Expression levels by tumour type are different for $G L U L\left({ }^{*} p<0.05\right)$ but not for ASNS (not significant). C GLUL expression values separated by a cut off value

were comparable, but higher in the other three tumor samples (Fig. 3C, D). RT-qPCR revealed an increased expression of $A S N S$ for all HB samples except sample HB12 compared to normal liver tissue (Fig. 3B). Under the experimental conditions adopted for the Western blot
B

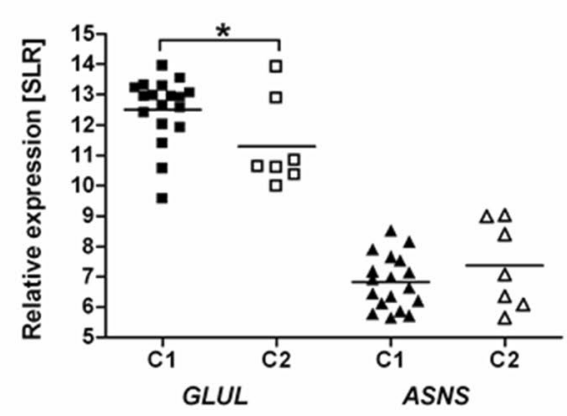

D

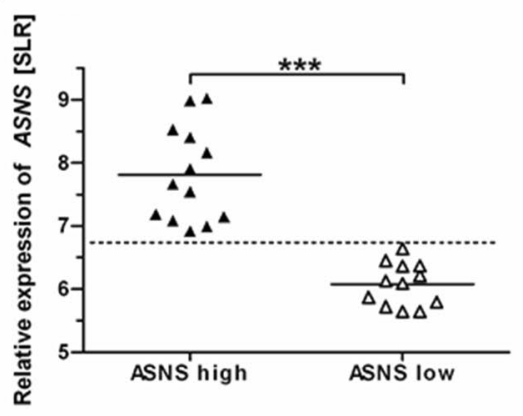

$\mathbf{F}$

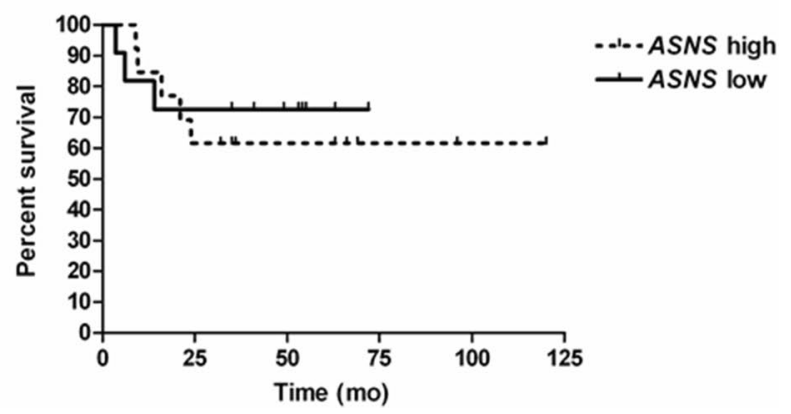

of SLR 12.0. Significant difference between high and low expression group $(* * * p<0.001)$. D ASNS expression values separated by a cut off value of SLR 6.75. Significant difference between high and low expression group $(* * * p<0.001)$. E Kaplan-Meier survival curves stratified according to high and low GLUL expression. Median overall survival time is 68 months for the low GLUL expression group, but not reached for the high GLUL expression group. Log rank test for group comparison $p=0.1855$. F Kaplan-Meier survival curves stratified according to high and low ASNS. Median overall survival not defined for the groups. Log rank test for group comparison $p=0.7125$.

analysis, ASNS was not detectable in normal liver tissue or HB samples. 
Table 1 Hepatoblastoma samples. Histology and mutation

\begin{tabular}{lll}
\hline Tumor sample & Histology & CTNNB1 mutation \\
\hline HB12 & Epithelial fetal & p.D32V, c.95A $>$ T \\
HB16 & Epithelial fetal ( $>80 \%$ fetal) & No \\
HB43 & Mixed (40\% mesenchymal, & No \\
& $60 \%$ epithelial (45\% fetal, & \\
& 15\% embryonal)) & \\
HB53 & Epithelial embryonal & p.G34E, c.101G $>$ A \\
HB56 & Epithelial fetal & No \\
\hline
\end{tabular}

$p$ protein sequence, $c$ coding DNA sequence

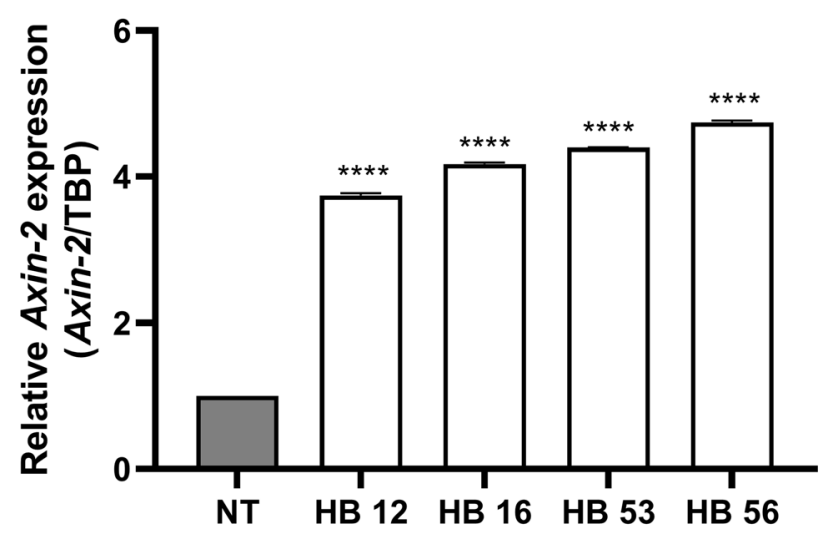

Fig. 2 Axin-2 expression in HB tissue samples. Axin-2 expression was normalized to expression of $T B P$. Significant increase in tissue samples compared to normal liver tissue (NT). Data show means $\pm \mathrm{SD}(n=3) . * * * * p<0.0001$ vs. NT. mRNA of HB sample 43 could not be extracted

\section{Embryonal hepatoblastoma cell cultures-GLUL and ASNS expression, corresponding protein levels and effect of ASNase and MSO}

To investigate specifically embryonal HB cell lines, we investigated the expression of GLUL and ASNS in the HB cell lines Huh-6 and HepT1. We also assessed the effect of glutamine depletion due to the GS inhibitor MSO and ASNase, which hydrolyses Asn and Gln, on GLUL and ASNS expression, levels of the two proteins and cell viability.

Huh-6 and HepT1 cells exhibited comparable expression levels of GLUL (Fig. 4A), but ASNS was four-fold more expressed in HepT1 than in Huh-6 cells ( $p<0.01$, Fig. 4B). At protein level, GS and ASNS were clearly detectable in both cell lines and showed comparable expression levels (Fig. 4C-E).

Treatment with ASNase alone caused a slight decrease of cell number (Fig. 4F and G) and cell viability (Fig. 4H and I) in both hepatoblastoma cell lines. ASNase combined with $1 \mathrm{mM}$ MSO reduced the cell number by more than $90 \%$ in both cell lines (Fig. 4F and G), and the cell viability by around $70 \%$ in Huh- 6 cells (Fig. $4 \mathrm{H}$ ) and by around $40 \%$ in the HepT1 cells (Fig. 4I). The EC50 for the dose-response curves of the combination therapy was in the range of 0.01-0.1 U/ml ASNase with $1 \mathrm{mM}$ MSO. MSO alone had no effect on cell number and viability of HuH6 cells (Fig. 4F and $\mathrm{H}$ ). In HepT1 cells, MSO did not impair cell viability (Fig. 4I) but reduced cell number by about 25\% (Fig. 4G). Changes in cell viability (Fig. $4 \mathrm{H}$ and I) determined by the MTT assay are in line with the results of the cell count investigation and show strong inhibition by the combination treatment but not by treatment with the single substances. The small effect of MSO on cell number of HepT1 cells is not seen in Huh-6 cells.

Treatment with ASNase alone increased GS protein in both cell lines more than the treatment with a combination of ASNase and MSO (Fig. 5A-C, E). In both cell lines, ASNS protein was also increased after ASNase treatment alone, whereas the combination treatment led to a decrease of ASNS protein (Fig. 5A, B, D, E).

Treatment of the cell lines with ASNase had little effect on GS mRNA (Fig. 6A, C). Its combination with MSO led to a small decline of GS mRNA in Huh-6 cells (Fig. 6A) and an increase in HepT1 cells (Fig. 6C). Both treatments led to an increase in ASNS mRNA concentration in both cell lines, which was more pronounced with the combination treatment (Fig. 6B, D).

\section{Discussion}

The analysis of microarray data points to a higher GLUL expression compared to normal liver tissue in all but one hepatoblastoma samples. Since activation of the $\mathrm{Wnt} / \beta$ catenin signaling pathway promotes $G L U L$ expression, high expression is an expected consequence of the high prevalence of activating mutations of components of this pathway in HB.

Stratification into high and low GLUL expression indicates a higher median overall survival time for patients with high expression of the enzyme. Cairo et al., who collected the data via microarray, distinguished a $\mathrm{C} 1$ versus a $\mathrm{C} 2$ type $\mathrm{HB}$ on the basis of a gene signature comprising 16 genes with statistically significant differences in 2-year overall survival rates of $92 \%$ and $44 \%$ respectively $(p<0.001)$. Interestingly, although $\mathrm{C} 1$ and $\mathrm{C} 2 \mathrm{HB}$ significantly differ for GLUL expression (Fig. 1B), the $\mathrm{C} 1$ group also includes $12.5 \%$ tumors with low $G L U L$ expression, and vice versa, the $\mathrm{C} 2$ group includes $37.5 \%$ hepatoblastomas with high GLUL expression. The activated Wnt pathway causes high expression of $G L U L$ with low variation. ASNS expression in normal cells is primarily regulated by the Amino Acid Response (AAR), and the Unfolded Protein Response (UPR) pathway. For tumors, an influence by other factors such as 

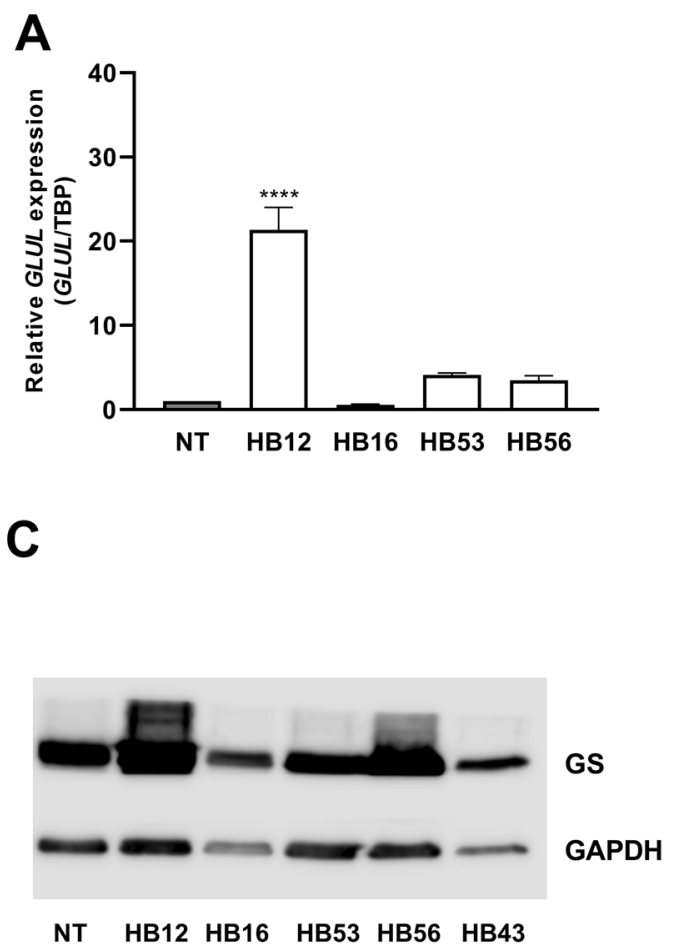

Fig. 3 Gene expression and GS protein abundance in HB tissue samples. A GLUL expression. GS mRNA is higher than in normal tissue (NT) in all but HB16 tissue samples. mRNA of HB sample 43 could not be extracted. GLUL expression was normalized to expression of TBP. Data show means \pm SD $(n=3)$. B ASNS expression. ASNS mRNA in the HB tissue samples is increased in all samples but HB12

p53 has also been described (Chiu et al. 2019). The lack of a corresponding activation of ASNS expression as present for GLUL expression that overrides possible regulatory mechanisms for expression explains the lower expression of ASNS and its larger variation.

The tumorigenesis of hepatoblastoma can explain the higher median overall survival time in high GLUL expressing patients, while in fact a worse prognosis could be expected given the positive effects of Gln on cell viability and proliferation. An embryonic cancer stem cell, or a multipotent stem cell with the potential to develop either to an epithelial or to a mesenchymal direction, is considered the original cell of hepatoblastoma. Malignant transformation at different stages of development or arrest of a transformed cell at a certain stage of differentiation lead to the formation of tumor subtypes. The embryonal and fetal tumor subtypes have gene profiles similar to the corresponding developmental stages of hepatogenesis. The fetal type is more differentiated, as indicated by the higher GLUL expression and GS abundance, and is endowed with the most favorable prognosis (Armengol et al. 2011; Cairo et al. 2008; Lopez-Terrada et al. 2009b; Sumazin et al. 2017). The favorable prognosis of the fetal tumor type
B
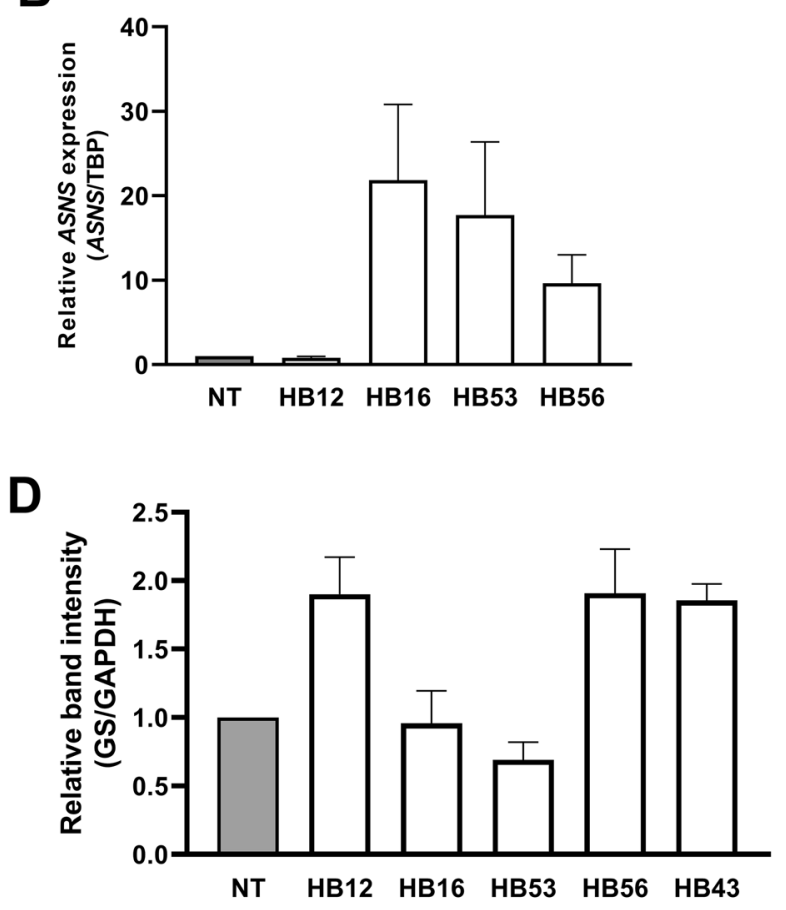

compared to normal liver tissue. mRNA of HB sample 43 could not be extracted. ASNS expression was normalized to expression of $T B P$. Data show means \pm SD $(n=3)$. C Western blot of GS. A representative experiment is shown. D Densitometric quantification. Relative ratio of GS/GAPDH density was normalized to ratio obtained in NT. Data show means $\pm \operatorname{SD}(n=5)$

is, therefore, consistent with the overall longer survival observed in the high GLUL group. Studies on the prognostic significance of gene signatures define different gene profiles, but they all have in common the overrepresentation of the fetal type in the prognostically more favorable group (Adesina, 2009; Cairo et al. 2008; Sumazin et al. 2017).

The hepatoblastoma panel examined here was very heterogeneous, consisting of different tumor subgroups. All samples showed GLUL expression at both mRNA and protein level. A mutation in the CTNNBI gene was found only in two samples. Investigations in different cell lines and tumor types have shown that these mutations affect the ubiquitination recognition motif of $\beta$-catenin leading to its decreased degradation and nuclear accumulation and in this way to activation of the Wnt pathway (Al-Fageeh et al. 2004; Lasota et al. 2015; Terris, 1999). The mutations were found in a variety of tumors such as hepatocellular carcinoma, central nervous system tumors, pancreatic and endometrial tumors (COSMIC 2021; Kim and Jeong 2019). A modest correlation between $C T N N B 1$ gene mutations and GLUL expression at the protein level determined by GS staining was also 
A

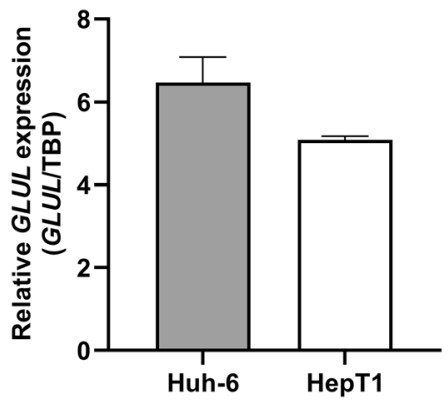

B

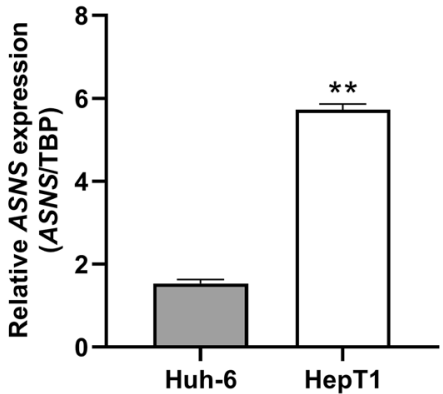

C

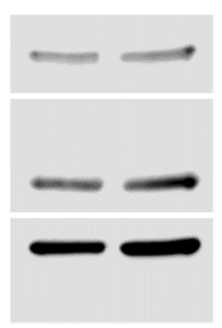

Huh-6 HepT1

ASNS

GS

GAPDH

D

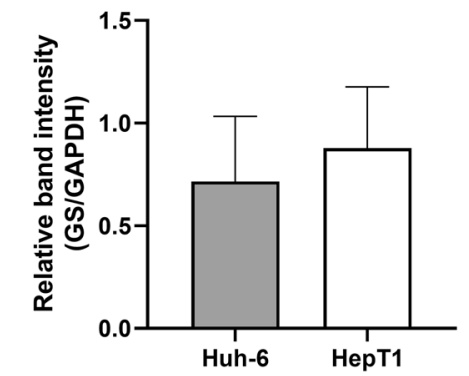

E

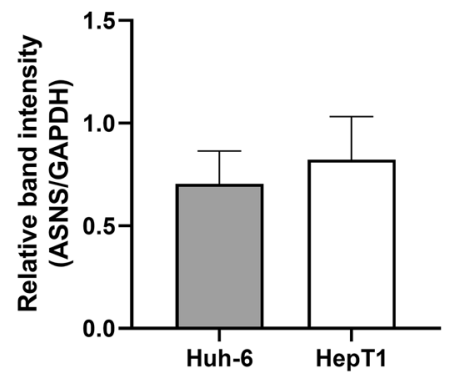

$\mathbf{F}$

Huh-6

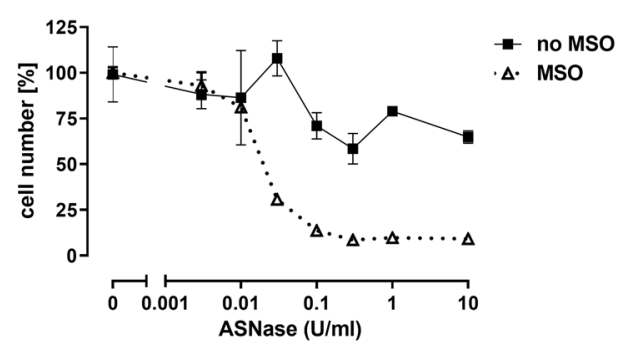

H

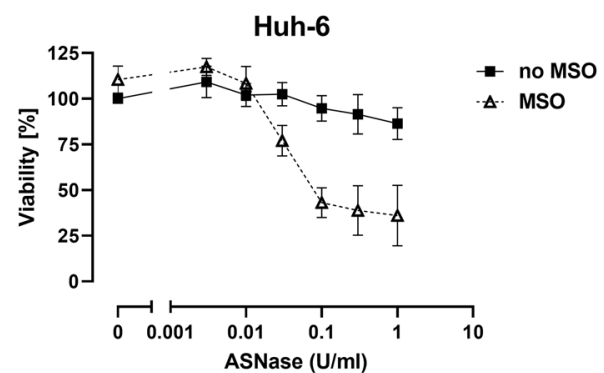

Fig. 4 Gene expression, protein abundance and effect of glutamine depletion in HB cell lines. A GLUL expression. GS mRNA levels in Huh-6 and HepT1 cells are comparable. GLUL expression was normalized to expression of TBP. Data show means \pm SD $(n=3)$. B ASNS expression. Significantly higher ASNS mRNA level in HepT1 cells $\left({ }^{*} p<0.01\right)$. ASNS expression was normalized to expression of TBP. Data show means \pm SD $(n=3)$. C Western blot of GS and ASNS. A representative experiment is shown. d Densitometric quantification of GS band. Data show means $\pm \mathrm{SD}(n=5)$. e Densitometric quantification of ASNS band. Data show means $\pm \operatorname{SD}(n=5)$. GS and
G

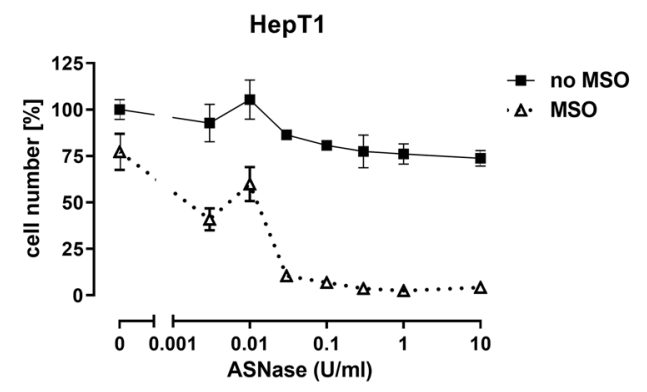

I

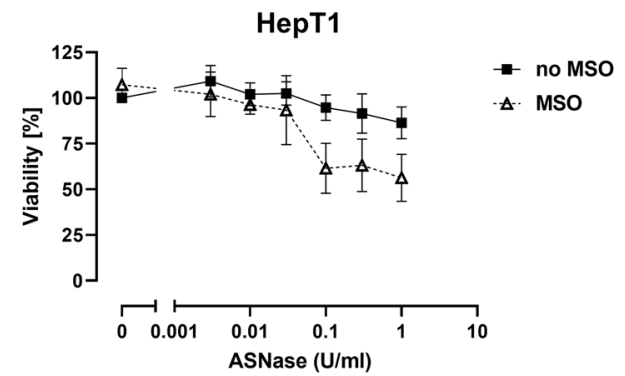

ASNS protein abundances in Huh-6 and in HepT1 cells is comparable. $\mathbf{f}$ Effect of glutamine depletion on cell number in Huh-6 cells. G Effect of glutamine depletion on cell number in HepT1 cells. H Effect of glutamine depletion on cell viability in Huh- 6 cells. I Effect of glutamine depletion on cell viability in HepT1 cells. In each experiment, treatment with the combination showed a greater effect than the treatment with the single substances. Results are expressed as per cent $[\%]$ of untreated control cultures. Data show means \pm SD $(n=3)$. The logarithmic plot of the $X$-axis is modified to show the values without ASNase. If MSO was used, the concentration was $1 \mathrm{mM}$ 
A

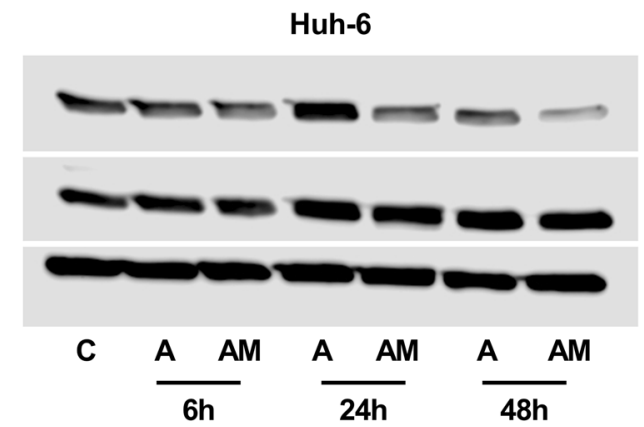

C

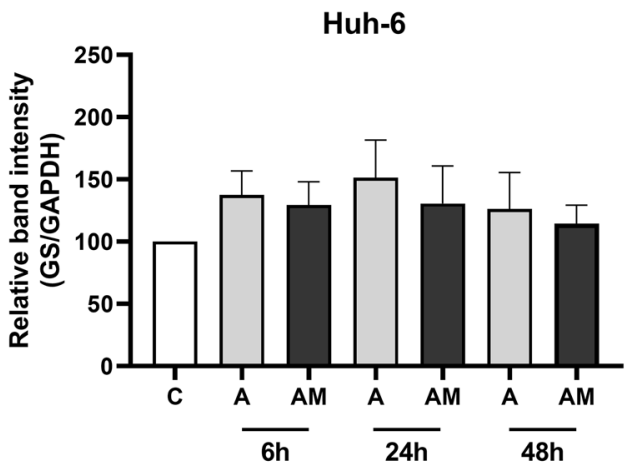

E

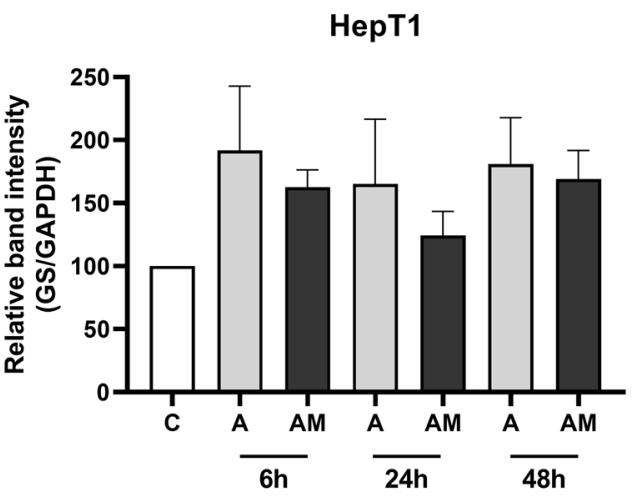

Fig. 5 Effect of ASNase (A) and ASNase + MSO (AM) on GS and ASNS protein abundance in HB cell lines. A Western blot of GS and ASNS in Huh-6 cells and B in HepT1 cells. Representative experiments are shown. C Densitometric quantification of GS band in Huh-6 cells and $\mathbf{E}$ in HepT1 cells. ASNase increases GS protein abundance more than ASNase+MSO. D Densitometric quanti-

found in samples of hepatocellular adenoma and carcinoma (Hale, 2016).

Since mutations in genes other than CTNNBI can also lead to an activation of the $\mathrm{Wnt} / \beta$-catenin signaling pathway, it cannot be excluded that an activated signaling pathway was present in the other samples. Therefore, we analyzed the HB samples for expression of Axin-2, another target gene
B

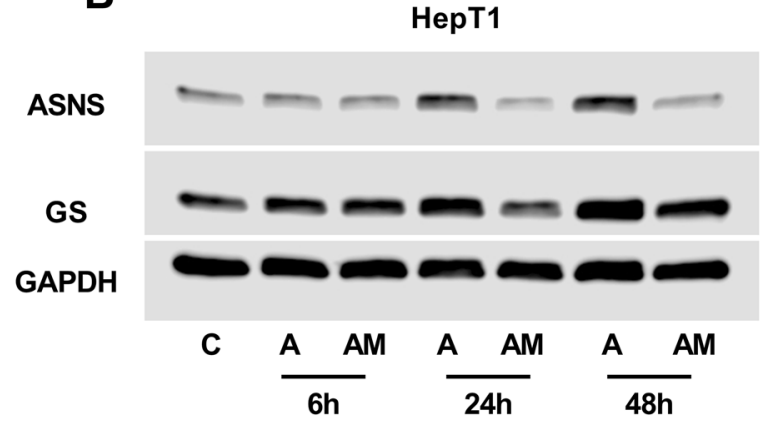

D

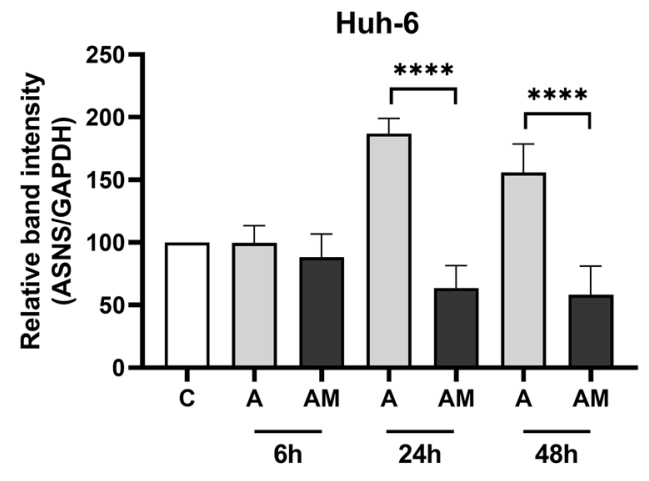

$\mathbf{F}$

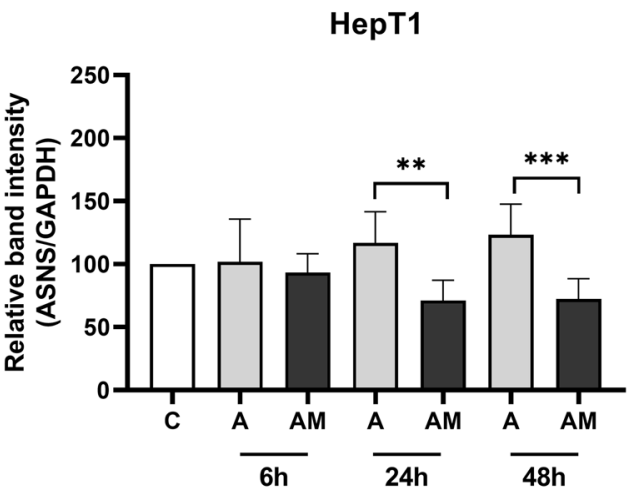

fication of ASNS band in Huh-6 cells and $\mathbf{f}$ in HepT1 cells. ASNS protein abundance is increased by ASNase, but reduced by ASNase + MSO. Relative ratio of GS/GAPDH density and of ASNS/ GAPDH density were normalized to ratio obtained in NT. Data show means $\pm \mathrm{SD}(n=5) . * * p<0.01 ; * * * p<0.001 ; * * * * p<0.0001$

of the Wnt/ $\beta$-catenin signaling pathway. All HB samples showed increased Axin-2 expression, indicating that an activated $\mathrm{Wnt} / \beta$-catenin signaling pathway may be present in samples without CTNNB1 mutation.

Since a single hepatoblastoma usually consists of different subtypes in varying proportions, it is difficult to reach definite conclusions from data obtained from tissue 
A

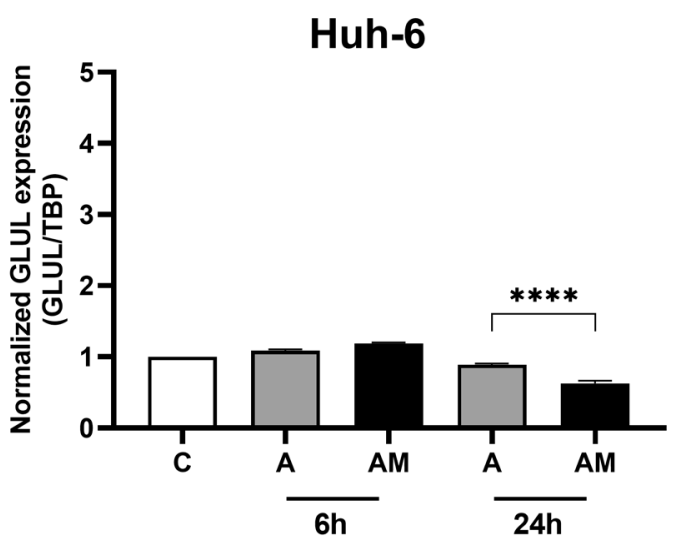

C

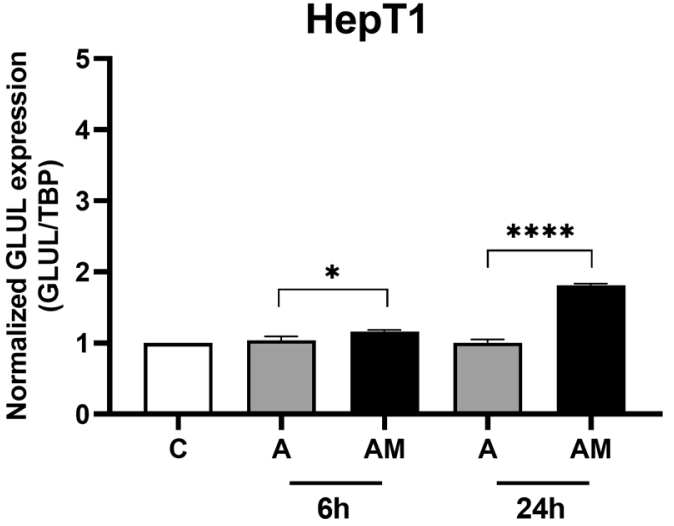

Fig. 6 Effect of ASNase (A) and ASNase + MSO (AM) on ASNS and $G L U L$ expression in HB cell lines. A GLUL expression in Huh-6 cells and $\mathbf{C}$ in HepT1cells. GS mRNA is decreased in Huh-6 cells, but increased in HepT1 cells by ASNase + MSO. B ASNS expression in Huh- 6 cells and $\mathbf{D}$ in HepT1 cells. ASNS mRNA in both cell lines

homogenates, given that the results represent all the subtypes present in the sample. Investigations at the histological level are more appropriate for obtaining information on the tumor subtypes. In previous studies, we found that GS staining is evident in the epithelial areas, especially in those with fetal morphology, but not in areas with mesenchymal morphology (Schmidt et al. 2014). This corresponds to the results of other reports, although the frequent absence of GS staining in epithelial embryonal areas is also described (Huang et al. 2017).

Investigations on cell lines and xenotransplants can provide further information about tumor subtype-specific properties. The best studied example is the HepG2 cell line, which was originally described as a hepatocellular carcinoma cell line, but is now considered to be derived from a hepatoblastoma (Lopez-Terrada et al. 2009a). HepG2 has a large in-frame deletion in the CTNNB1 gene
B
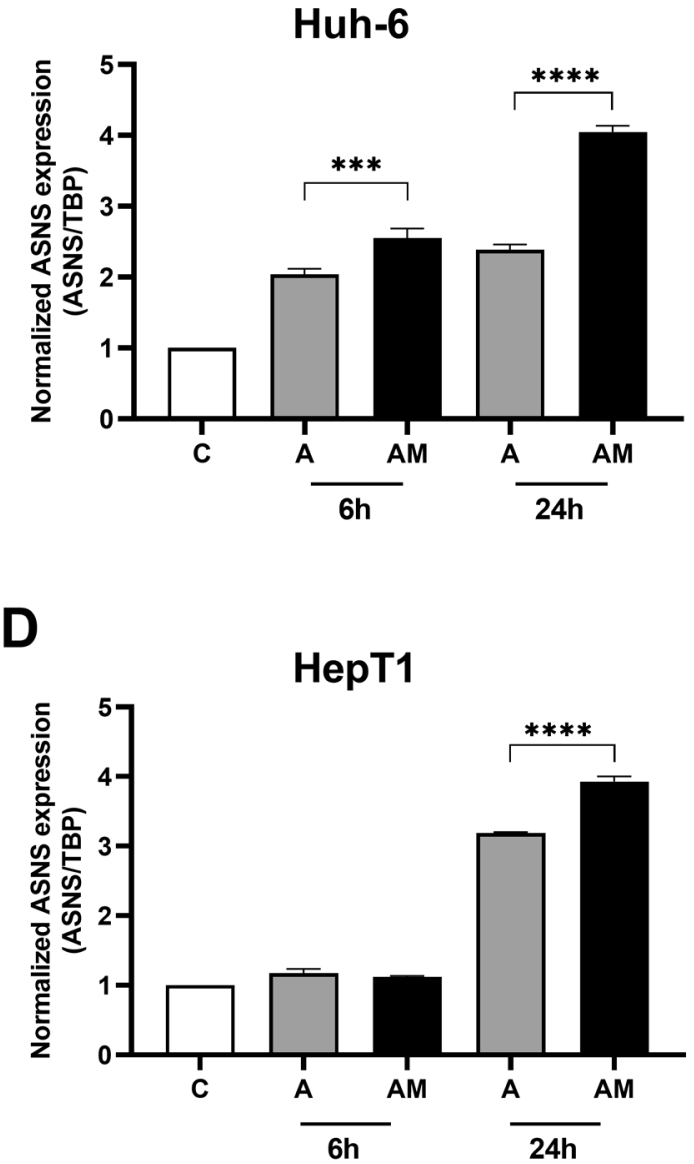

is increased more by the combination than by ASNase alone. Relative $G L U L$ expression (GLUL /TBP) and relative ASNS expression (ASNS /TBP) were normalized to expression in controls. Data show means $\pm \operatorname{SD}(n=3) . * p<0.05 ; * * * p<0.001 ; * * * * p<0.0001$

comprising 116 codons of exons 3 and 4 (Koch et al. 1999) and a mutation of the TERT promoter (Cevik et al. 2015) and represents the fetal tumor subtype with high GLUL expression and GS abundance (Lopez-Terrada et al. 2009b). Depletion of glutamine by a combination of the inhibitor of the glutamine synthetase methionine L-sulfoximine and asparaginase, which hydrolyses also Gln (Covini, 2012), leads to a significant inhibition of cell growth in vitro and inhibition of the growth of xenograft in mice (Chiu et al. 2014; Tardito et al. 2011).

We have studied two cell lines which have different characteristics, carrying different mutations: Huh- 6 cells have a missense mutation in the CTNNB1 gene $(\mathrm{c} .101 \mathrm{G}>\mathrm{T})(\mathrm{de} \mathrm{La}$ Coste, 1998), which leads to activation of the Wnt/ $\beta$-catenin signaling pathway, and HepT1 cells carry a deletion of 76 codons in exon 3 of the CTNNB1 gene (Koch et al. 1999). The cell lines are assigned to the embryonal tumor subtype 
(Crippa et al. 2017; Pietsch et al. 1996). In both cell lines, a combination of methionine-L-sulfoximine and asparaginase inhibited cell growth more than treatment with these inhibitors alone.

Treatment with asparaginase increased GS protein levels in both cell lines (Fig. 5A-C, E), but not GS mRNA levels (Fig. 6A, C). An increase of GS protein but not GS mRNA was also observed in the fetal hepatoblastoma cell line HepG2 and in three hepatocellular carcinoma cell lines (Hep3B, Huh-7, PLC-PRF-7) treated with asparaginase (Tardito et al. 2011). GS abundance is regulated by Gln via transcriptional and post-transcriptional mechanisms (Arad et al. 1976; Crook and Tomkins 1978). In particular, a mechanism, which was analyzed in more detail, involves acetylation of GS triggered by high Gln concentration which leads to binding of the Cereblon protein followed by GS ubiquitination and degradation by the proteasome (Nguyen, 2016). In our experiments, cell lines showed higher GS abundance after exposure to ASNase than controls (Fig. 5A-C, E). The glutaminolytic effect of ASNase may have reduced the concentration of Gln and, thus, lead to a reduced degradation of GS and higher GS abundance compared to controls.

GS protein levels were less increased and GS mRNA more decreased by a combination of asparaginase and methionine-L-sulfoximine compared to ASNase-only treatment. Since the combination treatment leads to a stronger inhibition of cell growth, it can be assumed that it is also associated with a stronger impairment of cell functions including the ability to adapt to changing metabolic conditions. In both cell lines, ASNS transcription is induced by asparaginase and by its combination with methionine-Lsulfoximine. Provided that a functional ASNS is produced, this could explain the partial resistance to asparaginase in the absence of MSO.

It has been shown that mutations in the CTNNB1 gene lead to differential gene expression and metabolic patterns. In particular, it has been proposed that a large deletion in exon 3, with extension to exon 4 , is associated with the fetal tumor subtype (Cairo et al. 2008; Crippa et al. 2017; LopezTerrada et al. 2009b). However, to our knowledge, there are no analyses that assign differential gene patterns or metabolic patterns to different mutation types within the embryonal subtype. The investigations on embryonal cell lines with different mutations suggest that glutamine depletion could be effective regardless of the mutation type.

The Wnt/ $\beta$-catenin pathway interacts with other signaling pathways, as shown for Hippo/YAP pathway (Min, 2019; Tao, 2014). In addition, an impact of the tumor microenvironment on glutamine metabolism has been recently proposed (Castegna and Menga 2018), suggesting that complex relationships exist in vivo that are not easily documented in vitro. The investigation of glutamine sensitivity of malignant tumors must therefore be continued on models that take into account these possible complexities.

Glutamine depletion is effectively reducing cell viability of cell lines representing the fetal and embryonal subtype of hepatoblastoma and might be a therapeutic approach for these subtypes. The higher efficacy of a combination of ASNase and MSO compared to the efficacy of the single substances indicates that therapy by inhibiting GS alone may not achieve a sufficient glutamine depletion. Concomitant reduction of Gln concentration by hydrolytic cleavage may be required. As the tumor microenvironment can contribute to the glutamine supply of tumor cells (Castegna and Menga 2018), this could be more important for tumors than for cell lines. Glutamine synthetase immunostaining of tumor specimens may be helpful to identify tumors, for whom a therapy which includes GS inhibition seems suitable.

For adult hepatocellular carcinoma, ASNS has been proposed as a prognostic factor and described as a possible therapeutic target (Zhang et al. 2013). Our findings on ASNS in hepatoblastoma do not suggest that it has a comparable significance in hepatoblastoma. The microarray data show, indeed, no dependence of overall survival on ASNS expression.

\section{Conclusion}

In hepatoblastoma, high GLUL expression is associated with higher median overall survival, explained by the specific tumorigenesis pathway which includes the development of a more differentiated, prognostic favorable fetal subtype with high GLUL and GS expression. On the contrary, in contrast to hepatocellular carcinoma, asparagine synthetase is not a prognostic factor for survival in hepatoblastoma.

Since hepatoblastomas are usually composed by areas representing different subtypes with specific characteristics, it would be necessary to demonstrate the effectiveness of a therapeutic approach for each individual tumor subtype. However, our studies on cell lines carrying different mutations suggest that the comparatively malignant embryonal subtype is also responsive to glutamine depletion, as already shown for the fetal subtype. Further studies in more complex models, however, are needed to explore the efficacy of a tumor therapy targeting glutamine dependence of hepatoblastoma.

Funding Open Access funding enabled and organized by Projekt DEAL. Not applicable. 


\section{Declarations}

Conflict of interest The authors declare that they have no conflict of interest.

Ethical approval The study was approved by the Ethical Committee of the Medical Faculty of the University of Tuebingen and the University Hospital Tuebingen, Germany (Ref. 354/2018BO2).

Consent to participate Written informed consent for the use of hepatoblastoma tissue samples for scientific purposes was obtained for all individual participants included in the study.

Open Access This article is licensed under a Creative Commons Attribution 4.0 International License, which permits use, sharing, adaptation, distribution and reproduction in any medium or format, as long as you give appropriate credit to the original author(s) and the source, provide a link to the Creative Commons licence, and indicate if changes were made. The images or other third party material in this article are included in the article's Creative Commons licence, unless indicated otherwise in a credit line to the material. If material is not included in the article's Creative Commons licence and your intended use is not permitted by statutory regulation or exceeds the permitted use, you will need to obtain permission directly from the copyright holder. To view a copy of this licence, visit http://creativecommons.org/licenses/by/4.0/.

\section{References}

Adesina AM et al (2009) Gene expression profiling reveals signatures characterizing histologic subtypes of hepatoblastoma and global deregulation in cell growth and survival pathways. Hum Pathol 40:843-853. https://doi.org/10.1016/j.humpath.2008.10.022

Al-Fageeh M, Li Q, Dashwood WM, Myzak MC, Dashwood RH (2004) Phosphorylation and ubiquitination of oncogenic mutants of beta-catenin containing substitutions at Asp32. Oncogene 23:4839-4846. https://doi.org/10.1038/sj.onc.1207634

Arad G, Freikopf A, Kulka RG (1976) Glutamine-stimulated modification and degradation of glutamine synthetase in hepatoma tissue culture cells. Cell 8:95-101. https://doi.org/10.1016/00928674(76)90190-2

Armengol C, Cairo S, Fabre M, Buendia MA (2011) Wnt signaling and hepatocarcinogenesis: the hepatoblastoma model. Int J Biochem Cell Biol 43:265-270. https://doi.org/10.1016/j.biocel.2009.07. 012

Cadoret A et al (2002) New targets of beta-catenin signaling in the liver are involved in the glutamine metabolism. Oncogene 21:82938301. https://doi.org/10.1038/sj.onc.1206118

Cairo S et al (2008) Hepatic stem-like phenotype and interplay of Wnt/ beta-catenin and Myc signaling in aggressive childhood liver cancer. Cancer Cell 14:471-484. https://doi.org/10.1016/j.ccr.2008. 11.002

Castegna A, Menga A (2018) Glutamine synthetase: localization dictates outcome. Genes (basel). https://doi.org/10.3390/genes90201 08

Cevik D, Yildiz G, Ozturk M (2015) Common telomerase reverse transcriptase promoter mutations in hepatocellular carcinomas from different geographical locations. World J Gastroenterol 21:311317. https://doi.org/10.3748/wjg.v21.i1.311

Chiu M et al (2014) Glutamine depletion by crisantaspase hinders the growth of human hepatocellular carcinoma xenografts. Br J Cancer 111:1159-1167. https://doi.org/10.1038/bjc.2014.425

Chiu M, Taurino G, Bianchi MG, Kilberg MS, Bussolati O (2019) Asparagine synthetase in cancer: beyond acute lymphoblastic leukemia front. Oncol 9:1480. https://doi.org/10.3389/fonc.2019. 01480

COSMIC (2021) Catalogue of Somatic Mutations in Cancer httpn :// cancersangeracuk/cosmic/gene/analysis? $\mathrm{ln}=\mathrm{CTNNB} 1$ Accessed 5 June 2021

Covini D et al (2012) Expanding targets for a metabolic therapy of cancer: L-asparaginase. Recent Pat Anticancer Drug Discov 7:4-13. https://doi.org/10.2174/157489212798358001

Crippa S et al (2017) Mutant CTNNB1 and histological heterogeneity define metabolic subtypes of hepatoblastoma. EMBO Mol Med 9:1589-1604. https://doi.org/10.15252/emmm.201707814

Crook RB, Tomkins GM (1978) Effect of glutamine on the degradation of glutamine synthetase in hepatoma tissue-culture cells. Biochem J 176:47-52. https://doi.org/10.1042/bj1760047

Czauderna P, Lopez-Terrada D, Hiyama E, Haberle B, Malogolowkin MH, Meyers RL (2014) Hepatoblastoma state of the art: pathology, genetics, risk stratification, and chemotherapy. Curr Opin Pediatr 26:19-28. https://doi.org/10.1097/MOP.0000000000 000046

de La Coste A et al (1998) Somatic mutations of the beta-catenin gene are frequent in mouse and human hepatocellular carcinomas. Proc Natl Acad Sci USA 95:8847-8851. https://doi.org/10.1073/pnas. 95.15.8847

DeBerardinis RJ, Cheng T (2010) Q's next: the diverse functions of glutamine in metabolism, cell biology and cancer. Oncogene 29:313-324. https://doi.org/10.1038/onc.2009.358

Doi I (1976) Establishment of a cell line and its clonal sublines from a patient with hepatoblastoma. Gan 67:1-10

Eichenmuller M et al (2014) The genomic landscape of hepatoblastoma and their progenies with HCC-like features. J Hepatol 61:1312-1320. https://doi.org/10.1016/j.jhep.2014.08.009

Haas JE, Muczynski KA, Krailo M, Ablin A, Land V, Vietti TJ, Hammond GD (1989) Histopathology and prognosis in childhood hepatoblastoma and hepatocarcinoma. Cancer 64:1082-1095. https://doi.org/10.1002/1097-0142(19890901)64:5\%3c1082:: aid-cncr2820640520\%3e3.0.co;2-g

Haas JE, Feusner JH, Finegold MJ (2001) Small cell undifferentiated histology in hepatoblastoma may be unfavorable. Cancer 92:3130-3134. https://doi.org/10.1002/1097-0142(20011215) 92:12\%3c3130::aid-cncr10115\%3e3.0.co;2-\#

Hale $\mathrm{G}$ et al (2016) Correlation of exon 3 beta-catenin mutations with glutamine synthetase staining patterns in hepatocellular adenoma and hepatocellular carcinoma. Mod Pathol 29:13701380. https://doi.org/10.1038/modpathol.2016.122

Huang WJ, Tsai JH, Jeng YM (2017) Complementary roles of betacatenin and glutamine synthetase immunostaining in diagnosis of chemotherapy-treated and untreated hepatoblastoma. J Formos Med Assoc 116:549-553. https://doi.org/10.1016/j.jfma. 2016.09.013

Jia D et al (2014) Exome sequencing of hepatoblastoma reveals novel mutations and cancer genes in the Wnt pathway and ubiquitin ligase complex. Hepatology 60:1686-1696. https://doi.org/10. 1002/hep. 27243

Kim S, Jeong S (2019) Mutation hotspots in the $\beta$-catenin gene: lessons from the human cancer genome databases. Mol Cells 42:8-16. https://doi.org/10.14348/molcells.2018.0436

Koch A, Denkhaus D, Albrecht S, Leuschner I, von Schweinitz D, Pietsch T (1999) Childhood hepatoblastomas frequently carry a mutated degradation targeting box of the beta-catenin gene. Cancer Res 59:269-273

Koch A et al (2004) Mutations and elevated transcriptional activity of conductin (AXIN2) in hepatoblastomas. J Pathol 204:546554. https://doi.org/10.1002/path.1662

Lasota J, Felisiak-Golabek A, Aly FZ, Wang ZF, Thompson LD, Miettinen M (2015) Nuclear expression and gain-of-function beta-catenin mutation in glomangiopericytoma (sinonasal-type 
hemangiopericytoma): insight into pathogenesis and a diagnostic marker. Mod Pathol 28:715-720. https://doi.org/10.1038/ modpathol.2014.161

Livak KJ, Schmittgen TD (2001) Analysis of relative gene expression data using real-time quantitative PCR and the 2(-Delta Delta C(T)) Method. Methods 25:402-408. https://doi.org/10.1006/ meth.2001.1262

Lopez-Terrada D, Cheung SW, Finegold MJ, Knowles BB (2009a) Hep G2 is a hepatoblastoma-derived cell line. Hum Pathol 40:1512-1515. https://doi.org/10.1016/j.humpath.2009.07.003

Lopez-Terrada D et al (2009b) Histologic subtypes of hepatoblastoma are characterized by differential canonical Wnt and Notch pathway activation in DLK+ precursors. Hum Pathol 40:783794. https://doi.org/10.1016/j.humpath.2008.07.022

Lopez-Terrada D et al (2014) Towards an international pediatric liver tumor consensus classification: proceedings of the Los Angeles COG liver tumors symposium. Mod Pathol 27:472-491. https:// doi.org/10.1038/modpathol.2013.80

Lukey MJ, Wilson KF, Cerione RA (2013) Therapeutic strategies impacting cancer cell glutamine metabolism. Future Med Chem 5:1685-1700. https://doi.org/10.4155/fmc.13.130

Malogolowkin MH, Katzenstein HM, Meyers RL, Krailo MD, Rowland JM, Haas J, Finegold MJ (2011) Complete surgical resection is curative for children with hepatoblastoma with pure fetal histology: a report from the Children's Oncology Group. J Clin Oncol 29:3301-3306. https://doi.org/10.1200/JCO.2010.29. 3837

Martinez-Outschoorn UE, Peiris-Pages M, Pestell RG, Sotgia F, Lisanti MP (2017) Cancer metabolism: a therapeutic perspective. Nat Rev Clin Oncol 14:11-31. https://doi.org/10.1038/nrclinonc.2016.60

Mates JM, Di Paola FJ, Campos-Sandoval JA, Mazurek S, Marquez J (2020) Therapeutic targeting of glutaminolysis as an essential strategy to combat cancer. Semin Cell Dev Biol 98:34-43. https:// doi.org/10.1016/j.semcdb.2019.05.012

Min Q et al (2019) Beta-catenin and yes-associated protein 1 cooperate in hepatoblastoma pathogenesis. Am J Pathol 189:1091-1104. https://doi.org/10.1016/j.ajpath.2019.02.002

Monga SP (2015) Beta-Catenin signaling and roles in liver homeostasis injury, and tumorigenesis. Gastroenterology 148:1294-1310. https://doi.org/10.1053/j.gastro.2015.02.056

Mosmann T (1983) Rapid colorimetric assay for cellular growth and survival: application to proliferation and cytotoxicity assays. J Immunol Methods 65:55-63. https://doi.org/10.1016/00221759(83)90303-4

Nguyen TV et al (2016) Glutamine triggers acetylation-dependent degradation of glutamine synthetase via the thalidomide receptor cereblon. Mol Cell 61:809-820. https://doi.org/10.1016/j.molcel. 2016.02.032

Pietsch T, Fonatsch C, Albrecht S, Maschek H, Wolf HK, von Schweinitz D (1996) Characterization of the continuous cell line HepT1 derived from a human hepatoblastoma. Lab Invest 74:809-818
Schmid E, Xuan NT, Zahir N, Russo A, Yang W, Kuhl D, Faggio C, Shumilina E, Lang F (2014) Cell Physiol Biochem 34(3):943-54. https://doi.org/10.1159/000366311

Schulte ML et al (2018) Pharmacological blockade of ASCT2-dependent glutamine transport leads to antitumor efficacy in preclinical models. Nat Med 24:194-202. https://doi.org/10.1038/nm.4464

She X, Rohl CA, Castle JC, Kulkarni AV, Johnson JM, Chen R (2009) Definition, conservation and epigenetics of housekeeping and tissue-enriched genes. BMC Genomics 10:269. https://doi.org/ 10.1186/1471-2164-10-269

Still ER, Yuneva MO (2017) Hopefully devoted to Q: targeting glutamine addiction in cancer. Br J Cancer 116:1375-1381. https:// doi.org/10.1038/bjc.2017.113

Sumazin P et al (2017) Genomic analysis of hepatoblastoma identifies distinct molecular and prognostic subgroups. Hepatology 65:104-121. https://doi.org/10.1002/hep.28888

Tao J et al (2014) Activation of beta-catenin and Yap1 in human hepatoblastoma and induction of hepatocarcinogenesis in mice. Gastroenterology 147:690-701. https://doi.org/10.1053/j.gastro. 2014.05.004

Tardito S et al (2011) L-Asparaginase and inhibitors of glutamine synthetase disclose glutamine addiction of beta-catenin-mutated human hepatocellular carcinoma cells. Curr Cancer Drug Targets 11:929-943

Terris B et al (1999) Close correlation between beta-catenin gene alterations and nuclear accumulation of the protein in human hepatocellular carcinomas. Oncogene 18:6583-6588. https://doi. org/10.1038/sj.onc.1203051

Willert K, Nusse R (1998) Beta-catenin: a key mediator of Wnt signaling. Curr Opin Genet Dev 8:95-102. https://doi.org/10.1016/ s0959-437x(98)80068-3

Ye J et al (2018) Targeting of glutamine transporter ASCT2 and glutamine synthetase suppresses gastric cancer cell growth. J Cancer Res Clin Oncol 144:821-833. https://doi.org/10.1007/ s00432-018-2605-9

Zhang B et al (2013) Asparagine synthetase is an independent predictor of surgical survival and a potential therapeutic target in hepatocellular carcinoma. Br J Cancer 109:14-23. https://doi.org/10.1038/ bjc. 2013.293

Zimmermann A (2005) The emerging family of hepatoblastoma tumours: from ontogenesis to oncogenesis. Eur J Cancer 41:15031514. https://doi.org/10.1016/j.ejca.2005.02.035

Publisher's Note Springer Nature remains neutral with regard to jurisdictional claims in published maps and institutional affiliations. 